\title{
ADENO-ASSOCIATED VECTOR MEDIATED GENE TRANSFER OF TRANSFORMING GROWTH FACTOR - $\beta 1$ TO NORMAL AND OSTEOARTHRITIC HUMAN CHONDROCYTES STIMULATES CARTILAGE ANABOLISM
}

\author{
M Ulrich-Vinther ${ }^{* 1}$, C Stengaard ${ }^{1}$, E M Schwarz ${ }^{2}$, \\ M B Goldring ${ }^{3}$, and K Soballe ${ }^{1}$ \\ ${ }^{1}$ Department of Orthopaedics, Aarhus University Hospital, Aarhus, Denmark \\ ${ }^{2}$ The Center for Musculoskeletal Research, University of Rochester Medical Center, Rochester, NY, USA \\ ${ }^{3}$ Division of Rheumatology, Beth Israel Deaconess Medical Center, New England Baptist Bone \& Joint Institute, \\ Harvard Institutes of Medicine, Boston, MA, USA
}

\begin{abstract}
The objective of the present study was to investigate whether cartilage anabolism in human primary osteoarthritic chondrocytes could be improved by adenoassociated virus (AAV) vector-mediated gene transduction of transforming growth factor TGF- $\beta 1$ (TGF- $\beta 1$ ).

A bi-cistronic AAV-TGF- 31 -IRES-eGFP (AAV-TGF$\beta 1)$ vector was generated and used for transduction of a normal human articular chondrocyte cell line (tsT/AC62) and primary human osteoarthritic articular chondrocytes harvested from 8 patients receiving total knee joint arthroplasty. Transduction efficiency was detected by fluorescent microscopy for gene expression of enhanced green fluorescent protein (eGFP). TGF- $\beta 1$ synthesis was determined by ELISA. To assess the influence of TGF- $\beta 1$ gene therapy on chondrocyte cartilage metabolism, mRNA expressions of type II collagen, aggrecan, and matrix metalloproteinase 3 (MMP-3) were determined by quantitative real-time PCR.

AAV-TGF- $\beta 1$ transduction resulted in increased synthesis of TGF- $\beta 1$ in both osteoarthritic chondrocytes and the normal articular chondrocyte cell line. The expression levels of the transduced genes were correlated to "multiplicity of infection" (MOI) and post-infectious time. In both osteoarthritic chondrocytes and the normal articular chondrocyte cell line, AAV-TGF- $\beta 1$ treatment increased mRNA expression of both type II collagen and aggrecan, but decreased MMP-3 mRNA expression. Osteoarthritic chondrocytes and the normal articular chondrocyte cell line could be transduced with equal efficiencies.

In conclusion, it was demonstrated that AAV-TGF- $\beta 1$ gene transfer stimulates cartilage anabolism and decreases expression of enzymes responsible for cartilage degradation in human osteoarthritic chondrocytes. The results indicate that the AAV vector is an efficient mediator of growth factors to human articular chondrocytes, and that it might be useful in future chondrocyte gene therapy.
\end{abstract}

Keywords: Adeno-Associated Virus, Transforming Growth Factor- $\beta 1$, gene therapy, cartilage, osteoarthritis

*Address for correspondence:

M Ulrich-Vinther,

Department of Orthopaedics,

Aarhus University Hospital, Tage Hansens Gade 2,

DK-8000 Aarhus C, Denmark

Telephone: $(+45) 89497471$

Telefax: (+45) 89497429

E-mail: ulrich-vinther@mail.dk
Introduction

Articular cartilage injury (Alleyne et al., 2001; Browne et al., 2000; Kish et al., 1999; Martinek et al.,2001), and osteoarthritis (Frenkel et al.,1999; Malemud et al., 1999; Vangsness, 1999) remain serious clinical problems and, collectively, are among the most prevalent pathologies that affect human joints. Even though, the presence of mesenchymal stem-cells in articular cartilage has recently been reported (Alsalameh et al., 2004; Dowthwaite et al., 2004), the cartilage repair response to injury and osteoarthritis is inadequate (Buckwalter et al., 1998; Ulrich-Vinther et al., 2003). Hence, stimulation of deteriorated cartilage with growth factors may be attractive. Various studies have demonstrated that transforming growth factor TGF- $\beta 1$ (TGF- $\beta 1$ ) is one of the most potent of the various growth factors for cartilage repair (Grimaud et al., 2002). TGF- $\beta 1$ directly stimulates proteoglycan and collagen synthesis (Redini et al., 1988) and antagonizes the effects of IL-1 on matrix metalloproteinases (MMP) in normal and osteoarthritic chondrocytes (Andrews et al., 1989; Lum et al., 1996; van Beuningen et al., 2000; van der Kraan et al., 2000).

As cartilage damage and osteoarthritis affect a limited number of large, weight-bearing joints and have no major extra-articular manifestations, they might be well suited for local, intra-articular gene therapy by which the chondrocytes can be long-term stimulated by chondroanabolic growth factors such as TGF- $\beta 1$. Previous studies have reported gene delivery into human chondrocytes with the use of naked DNA and viral vectors (Arai et al., 1997; Baragi et al., 1997; Doherty et al., 1998; Kang et al., 1997). However, problems with these gene transfer methods are related to the ability to obtain high-efficiency transduction, to maintain long-term expression of the therapeutic gene, and appropriate safety profiles of the vector systems. Recently, vectors based on the adenoassociated virus (AAV) have convincingly mediated transduction of reporter genes to human articular chondrocytes (Arai et al., 2000; Madry et al., 2003; Ulrich-Vinther et al., 2002). These studies have identified that the AAV vector is capable of efficient gene transfer and sustained gene expression in both normal primary articular chondrocyte cultures, and articular cartilage explants, and direct in vivo gene therapy (Ulrich-Vinther et al., 2004). Furthermore, gene therapy with AAV has several important advantages, including an attractive vector safety profile, and the ability of long-term expression in tissues with low mitotic rate (Schwarz, 2000). 
Therefore, we now have tested the potency of AAVTGF- $\beta 1$ gene transfer to increase cartilage anabolism in human articular chondrocytes derived from both normal articular cartilage and osteoarthritic joints from 8 human patients.

\section{Materials and Methods}

\section{Preparation of the AAV-TGF- $\beta 1$-IRES-eGFP vector}

Generation of the bi-cistronic rAAV type 2 transfer vector, rAAV-TGF- $\beta 1$-IRES-eGFP, was carried out via multiple subcloning steps as described previously (Ito et al., 2004; Ulrich-Vinther et al., 2002). In brief, the rAAV-TGF- $\beta 1$ IRES-eGFP vector was generated by replacing the OPG cDNA in the pAAV-OPG-IRES-eGFP (Ulrich-Vinther et al., 2002) with a porcine TGF- $\beta 1$ cDNA fragment that was subcloned into the NotI and EcoRI sites. The bi-cistronic insert was under transcriptional control of a CMV promoter Extensive restriction digests and double-stranded cDNA sequencing of the TGF- $\beta 1$ cDNA were performed to confirm the authenticity of the vector. Subsequently, 0.5 mg of pAAV-TGF- $\beta 1$-IRES-eGFP was sent to the Gene Core Facility, University of North Carolina at Chapel Hill, $\mathrm{NC}$, which prepared the purified rAAV-TGF- $\beta 1$-IRESeGFP, and also provided the rAAV-eGFP control vector using a helper virus free method (Xiao et al., 1998). The concentration of infectious rAAV-TGF- $\beta 1$-IRES-eGFP units was approximately $4 \times 10^{12}$ infectious particles per $\mathrm{mL}$ determined by titration on human embryonic kidney 293 cells (Goater et al., 2002; Ulrich-Vinther et al., 2002).

\section{Human articular chondrocyte cultures}

Due to the limited access to normal human articular cartilage for primary cellular studies, the well-characterized normal adult human articular chondrocyte cell line, tsT/ AC62, immortalized with a temperature-sensitive mutant of SV40 large T antigen (Robbins et al., 2000), was used. The tsT/AC62 cells were cultured routinely for proliferation in monolayer cultures at $32^{\circ} \mathrm{C}$ in a humidified sterile atmosphere of $95 \%$ air and $5 \% \mathrm{CO}_{2}$. The cells were passaged every 7-10 days at a split ratio of $1: 2$. For transduction experiments, the tsT/AC62 cells were plated in 6-well tissue culture plates at a density of $10^{6}$ cells per well ( $\sim 80 \%$ confluence) in Dulbecco's modified Eagle's medium (DMEM) / Ham's F-12 (1:1) (Gibco BRL, Gaithersburg, MD, USA) at an increased temperature of $37^{\circ} \mathrm{C}$ in a humidified sterile atmosphere of $95 \%$ air and $5 \% \mathrm{CO}_{2}$. The tsT/AC62 cell cultures were transduced 24 hours after plating.

Additionally, osteoarthritic articular cartilage was harvested from the knee joints of 8 patients undergoing total knee arthroplasty surgery due to severe primary osteoarthritis. The population was constituted of 4 females and 4 males with a mean group age of 66.4 years \pm 3.1 years (mean $\pm \mathrm{SEM}$ ). Beside paracetamol, the patients did not receive any medicine. The Danish Ethical Committee approved the use of human cartilage, and informed consent was obtained from all patients included. The cartilage specimens from the 8 patients were kept separately for individual gene transductions, cultures and paired analyses. Immediately after harvesting, the articular cartilage specimens from the 8 patients were carefully dissected from the subchondral bone, and finely chopped. The fragments were washed twice with sterile phosphate buffered saline. The chondrocytes were liberated from the extra-cellular matrix by a two-step enzymatic digestion including a brief hyaluronidase digestion with $1 \%$ testicular hyaluronidase (Sigma, St. Louis, MO, USA) in DMEM/Ham's F-12 for 1 hour, and a prolonged collagenase digestion with $1 \%$ clostridial collagenase A (Sigma, St. Louis, MO, USA) in DMEM/Ham's F-12 for 24 hours. These digestions were performed under vigorous shaking at $37^{\circ} \mathrm{C}$. The isolated chondrocytes were filtered (Swinnex filter with $40 \mathrm{~mm}$ pores (Millipore, Bedford, MA, USA)), and resuspended in DMEM/Ham's F-12 (1:1). The chondrocytes were seeded onto 6-well plastic plates at a density of $10^{6}$ cells per well and cultured in Dulbecco's modified Eagle's medium (DMEM) / Ham's F-12 $(1: 1)$ at $37^{\circ} \mathrm{C}$ in a humidified sterile atmosphere of $95 \%$ air and $5 \% \mathrm{CO}_{2}$. The cultures were transduced 24 hours after plating.

Maintenance of the chondrocyte differentiation during the experiments was confirmed by reverse transcriptionPCR for markers of articular chondrocyte maturity (aggrecan and types I, II, and X collagen).

\section{Detection of transduction efficiency}

The human articular chondrocyte cultures were transduced with AAV-TGF- $\beta 1$-IRES-eGFP at MOIs of either 250, or 1000. Control cultures consisted of uninfected cultures and cultures infected with the AAV-eGFP vector at a MOI of 1000 .

At days $0,2,4,6$, and 8 after transduction, the transduction efficiency of the AAV-TGF- $\beta 1$-IRES-eGFP vector was determined as the relative population of green fluorescent chondrocytes in the cultures by fluorescent microscopy. Determinations of the relative population of green fluorescent chondrocytes were based counts of 250 chondrocytes. Uninfected articular chondrocytes were analyzed simultaneously and confirmed non-fluorescent.

\section{Detection of TGF- $\beta 1$ synthesis}

At days $0,2,4,6$, and 8 after transduction, concentrations of active TGF- $\beta 1$ in the culture supernatants were determined by enzyme-linked immunosorbent assay (ELISA), using the porcine ELISA kit "TGF- $\beta 1$ Duo Set" with TGF-TGF- $\beta 1$ protein standards (Quantikine, R\&D Systems, Minneapolis, MN, USA). The corresponding total concentrations of TGF- $\beta 1$ (latent + active) were determined with ELISA by activation of the latent TGF$\beta 1$ to the immunoreactive form by acid activation according to manufactures instructions (Quantikine, R\&D Systems, Minneapolis, MN, USA). Uninfected and AAVeGFP transduced primary human articular chondrocytes and tsT/AC62 chondrocytes served as negative controls.

\section{Detection of TGF- $\beta 1$, type II collagen, aggrecan and MMP-3 expression}

At 8 days after transduction, total RNA was extracted using 
Table 1. Primer sequences used for RT-PCR amplification of TGF- $\beta 1$, type II collagen, aggrecan, and MMP-3

\begin{tabular}{|c|c|c|c|}
\hline Gene & & Primer & Size (bp) \\
\hline \multirow[t]{2}{*}{ TGF-beta 1} & s & 5' GAGCAGCACGTGGAGCT 3' & \multirow{2}{*}{108} \\
\hline & as & 5' CAACTCCGGTGACATCAAA 3' & \\
\hline \multirow[t]{2}{*}{ Type II collagen } & $s$ & 5' GGACTTTTCTCСССТCTCT 3' & \multirow{2}{*}{113} \\
\hline & as & 5' GACCCGAAGGTCTTACAGGA 3' & \\
\hline \multirow[t]{2}{*}{ Aggrecan } & $s$ & 5' TCGAGGACAGCGAGGCC 3' & \multirow{2}{*}{94} \\
\hline & as & 5' TCGAGGGTGTAGCGTGTAGAGA 3' & \\
\hline \multirow[t]{2}{*}{ MMP-3 } & s & 5' TGGTACCCACGGAACCTGTC 3' & \multirow{2}{*}{59} \\
\hline & as & 5' GATCACAGTTGGCTGGCGTC 3' & \\
\hline
\end{tabular}

the RNeasy mini kit with the RNAse free DNase on column option (QIAGEN Inc., Venlo, Netherlands) and singlestranded cDNA was made using a reverse transcription kit (Bio-Rad iScript cDNA synthesis Kit, Bio-Rad Laboratories, CA, USA) according to manufactures instructions. The total RNA concentration was determined using Quant-It ${ }^{\mathrm{TM}}$ Ribogreen Kit (Molecular Probes Inc, OR, USA).

Real-time Polymerase Chain Reaction (PCR) was performed on the Stratagene MX4000 real-time amplification system using Stratagene Brilliant SYBR Green (Stratagene, CA, USA) according to the manufacturer's instructions. A cDNA equivalent to $6 \mathrm{ng}$ of total RNA was used in each reaction. Primers for TGF- $\beta 1$ and MMP3 were designed using Primer3 Software. Primer sequences for Type II collagen and aggrecan were kindly supplied by Jeff Goater, University of Rochester Medical Center, NY, USA (Table 1). Primers were manufactured by DNA-Technology, Aarhus, Denmark. For PCR, the primer concentration was $600 \mathrm{nM}$ in all reaction mix. All primers were optimised with regards to primer concentration, $\mathrm{MgCl}_{2}$ concentration and efficiency to achieve efficiency of $100 \%$ (Table 1 ).

The relative gene expression is a relative quantification in real-time PCR of a target gene transcript (AAV-TGF- $\beta 1$ transduced) in comparison to a reference gene transcript (Untransduced / AAV-GFP transduced). Hence, an effect of AAV-TGF- $\beta 1$ transduction on a target gene expression such as type II collagen, will be emphasized. The mean threshold cycle $(\mathrm{Ct})$ values from duplicate measurements were used to calculate the relative gene expression according to Pfaffl (Pfaffl, 2001) as:

$$
\text { Relative expression }=\mathrm{E} \quad \Delta \mathrm{Ct} \text { target }(\text { control }- \text { sample })
$$

...with $\mathrm{E}=2$ and with normalization to the total RNA concentration according to Bustin (Bustin, 2000) as internal control.

Uninfected and AAV-eGFP transduced primary human articular chondrocytes and tsT/AC62 chondrocytes served as negative controls.

\section{Statistical analysis}

The study was designed as a paired interventional experiment. All data acquisition and analyses were performed blindly. Cartilage samples from eight patients were harvested and analyzed separately. For each parameter, measurements were performed in doublets. The data confirmed proximities to normal distribution and homogeneity of variances and, hence, parametric analyses were applied (Students paired $t$-test). Statistical significance was determined as $p<0.05$ (two-tailed).

\section{Results}

\section{Transduction efficiency}

The AAV-TGF- $\beta 1$ vector convincingly mediated reporter gene delivery to both tsT/AC62 chondrocytes and osteoarthritic chondrocytes (Fig.1,A-B). From day 2 to day 8 after transduction, the percentage of eGFP expressing cells increased in all transduced groups (tsT/ AC62 chondrocytes: MOI 250; 487\% ( $<<0.001)$, MOI 1000; 471\% $(\mathrm{p}<0.001)$. Osteoarthritic chondrocytes: MOI 250; 583\% $(\mathrm{p}<0.001)$, MOI 1000; 649\% $(\mathrm{p}<0.001))$ (Fig.1,B). The transduction efficiencies were positively correlated to the MOIs (Fig.1,B). Cultures of tsT/AC62 chondrocytes and osteoarthritic chondrocytes were found to be equally transduced by the AAV vector (Fig. 1,B).

\section{Synthesis of TGF- $\beta 1$}

The results of TGF- $\beta 1$ ELISA-measurements are depicted in Fig. 2. Throughout the observation period, administration of AAV-TGF- $\beta 1$ resulted in increasing concentrations of both total and active TGF- $\beta 1$ in all groups (Fig. 2). Additionally, the level of TGF- $\beta 1$ synthesis depended on the MOI of AAV-TGF- $\beta 1$ in both tsT/AC62 chondrocytes and osteoarthritic chondrocytes. Eight days after transduction, infection of tsT/AC62 chondrocytes at a MOI of 1000 resulted in $123 \pm 11 \mathrm{ng} /$ $\mathrm{mL}$ of total TGF- $\beta 1$ and $12 \pm 1 \mathrm{ng} / \mathrm{mL}$ of active TGF$\beta 1$, whereas transduction at a MOI of 250 resulted in 46 $\pm 5 \mathrm{ng} / \mathrm{mL}$ of total TGF- $\beta 1$ and $5 \pm 1 \mathrm{ng} / \mathrm{mL}$ of active 


\section{A}
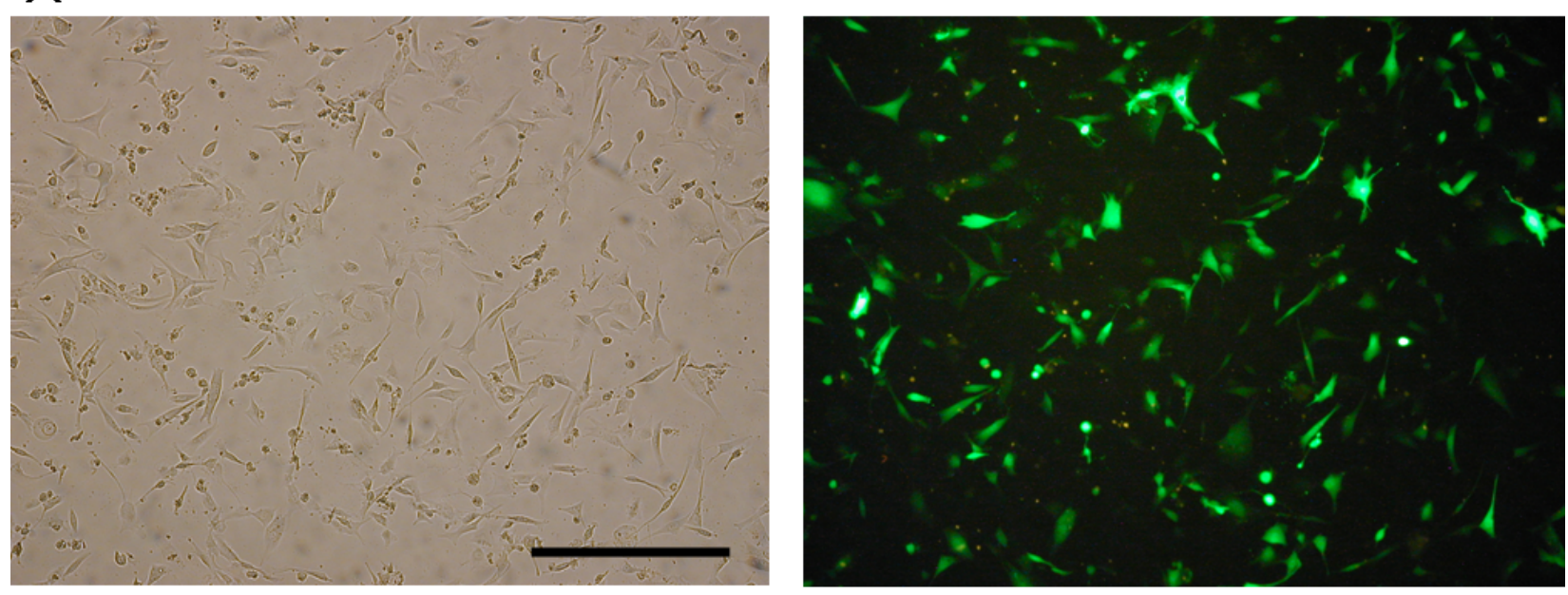

B

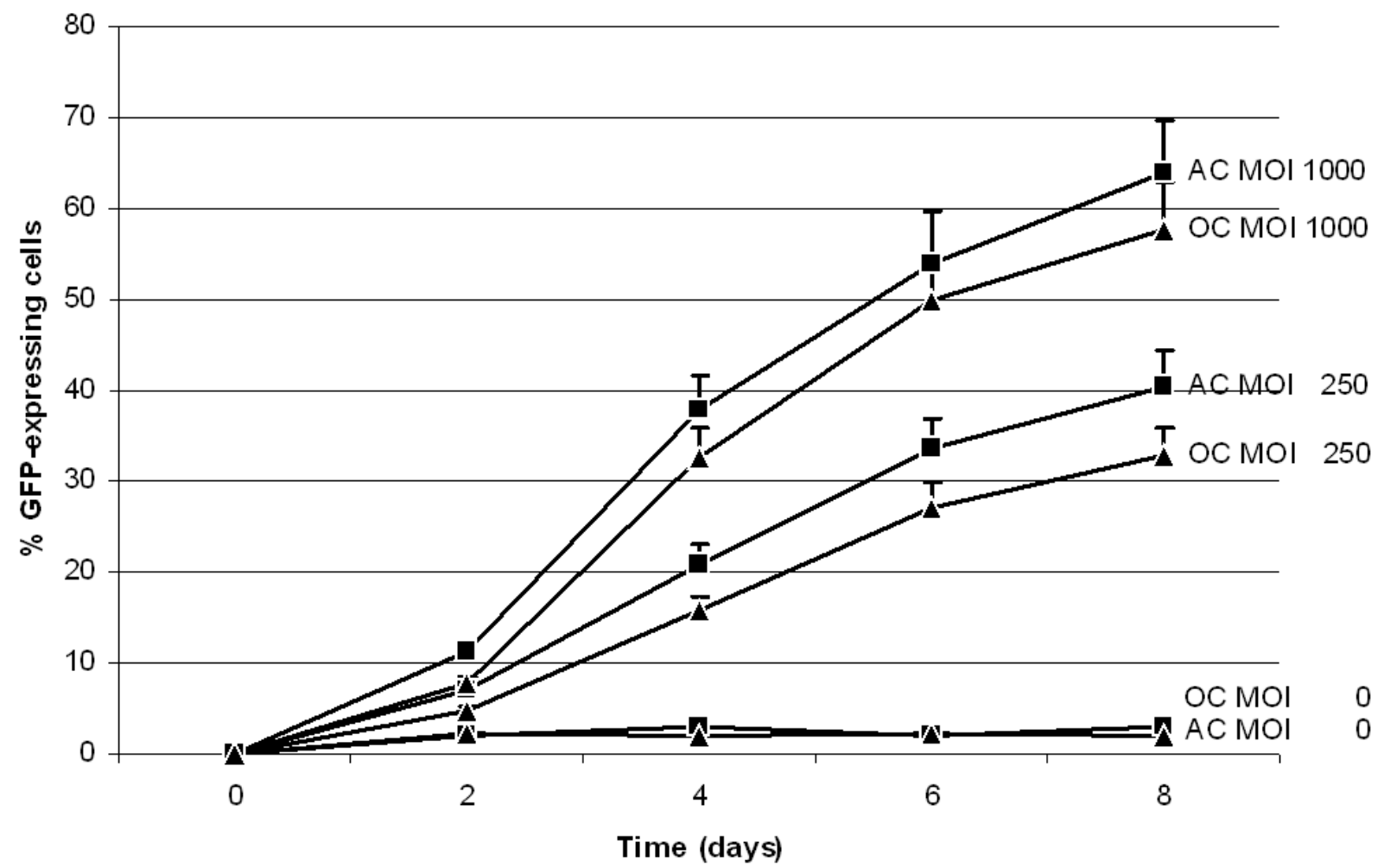

Figure 1 (A) Bright-field light (left) and fluorescence (right) microscopy of corresponding human osteoarthritic chondrocytes 8 days after AAV-TGF- $\beta 1$-IRES-eGFP transduction at a MOI of 1000 . Dimensions are given by scale bar $(100 \mathrm{~mm})$. (B) AAV-TGF- $\beta 1$-IRES-eGFP transduction of both osteoarthritic human chondrocytes and a human normal articular chondrocyte cell line resulted in an increasing number of eGFP expressing chondrocytes during the observation period (mean with SEM).

AC: normal human articular chondrocyte cell line. OC: human osteoarthritic chondrocytes.

MOI: multiplicity of infection.

TGF- $\beta 1$ (p (MOI 250 versus MOI 1000) $<0.05$ for both total and active TGF- $\beta 1)$. No difference in TGF- $\beta 1$ synthesis between tsT/AC62 chondrocytes and osteoarthritic chondrocytes was observed in any groups. No difference in TGF- $\beta 1$ concentrations in media from uninfected chondrocytes and AAV-eGFP transduced chondrocytes was observed (data not shown).
Expression of TGF- $\beta 1$, type II collagen, aggrecan, and MMP-3

The results of quantitative RT-PCR performed on extracted mRNA from articular chondrocytes at 8 days after transduction are given as cycle threshold $(\mathrm{Ct})$ in Fig. 3 and as relative gene expression in Table 2 .

AAV-TGF- $\beta 1$ transduction of both tsT/AC62 chondrocytes and osteoarthritic chondrocytes resulted in 


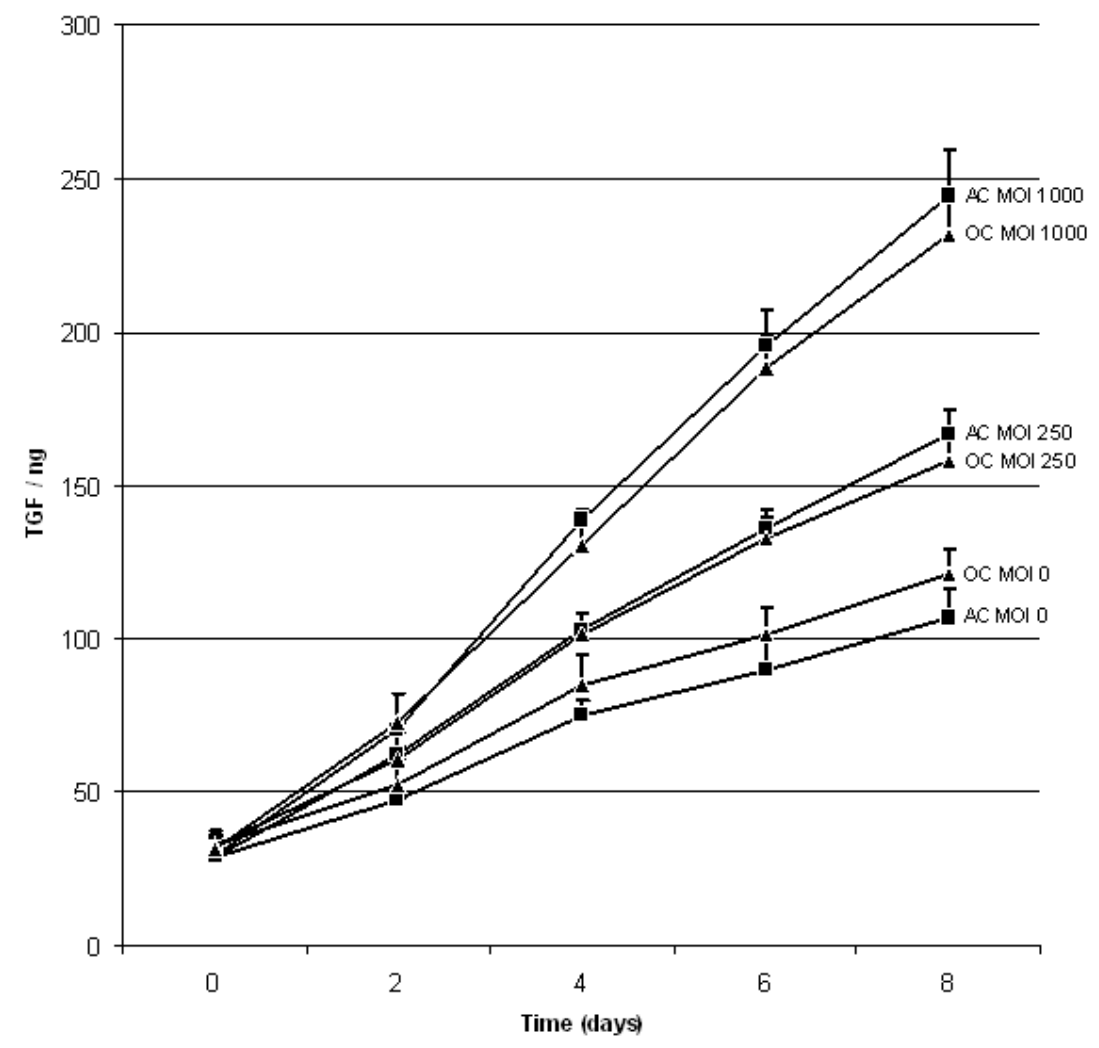

B

Accumulated synthesis of active TGF beta1

Figure 2 Synthesis of TGF- $\beta 1$ in primary osteoarthritic human chondrocytes and a normal human articular chondrocyte cell line following AAV-TGF- $\beta 1$ transduction. The synthesis of both latent (A) and active (B) TGF- $\beta 1$ in culture media from articular chondrocytes was determined by ELISA at days 0 , $2,4,6$, and 8 after transduction (mean with SEM). All cultures infected with AAV-TGF- $\beta 1$ produced significant amounts of TGF- $\beta 1$ compared with the controls (not transduced and AAV-eGFP transduced cells) $(p<0.05)$.

AC: normal human articular chondrocyte cell line. OC: human osteoarthritic chondrocytes. MOI: multiplicity of infection.

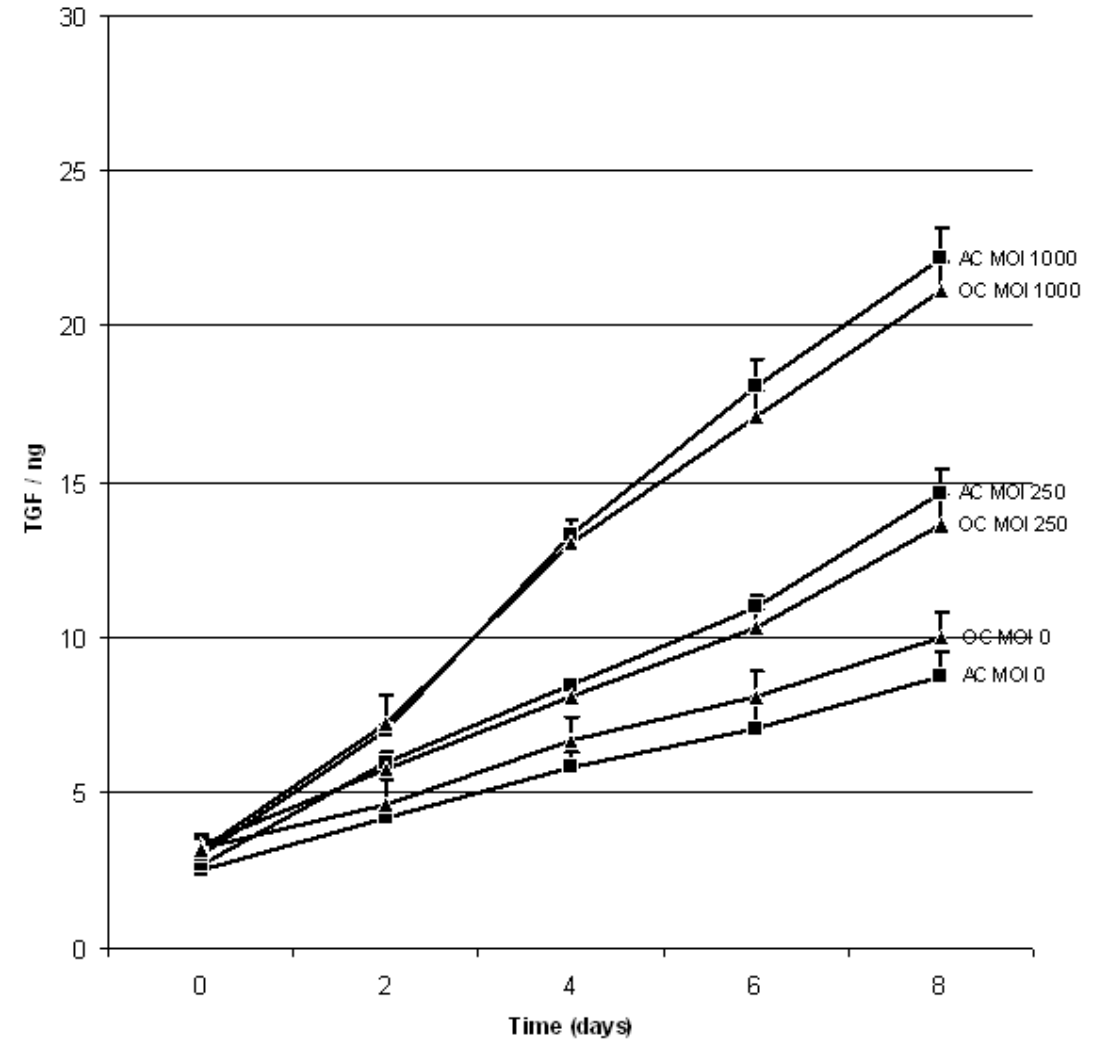


A

TGF-beta1

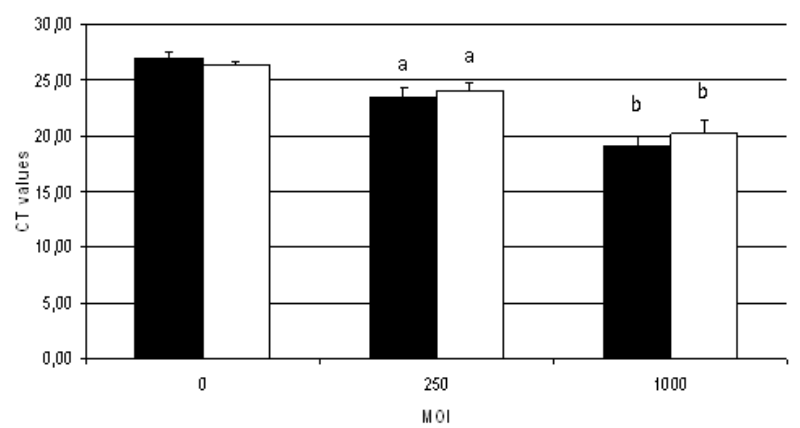

C

Aggrecan

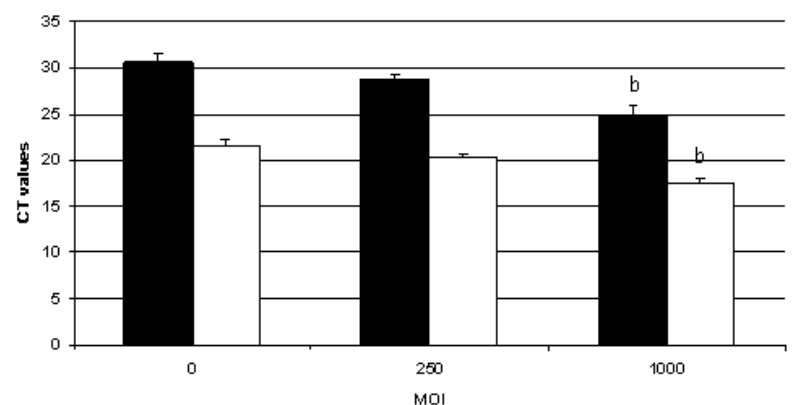

B

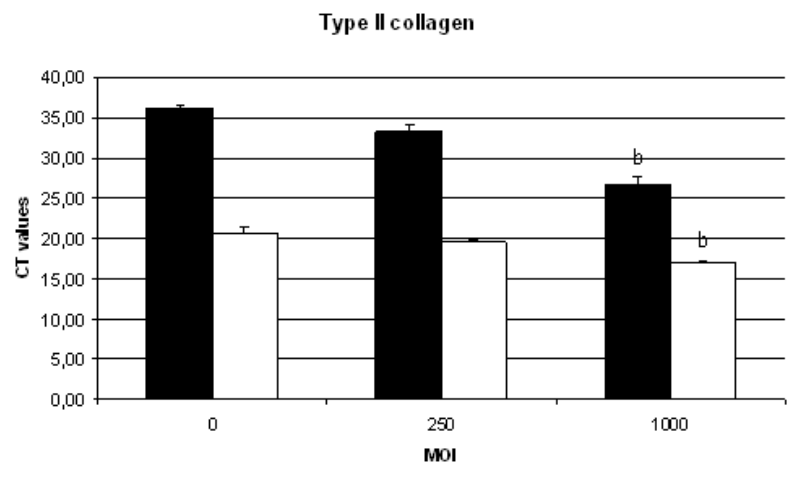

D

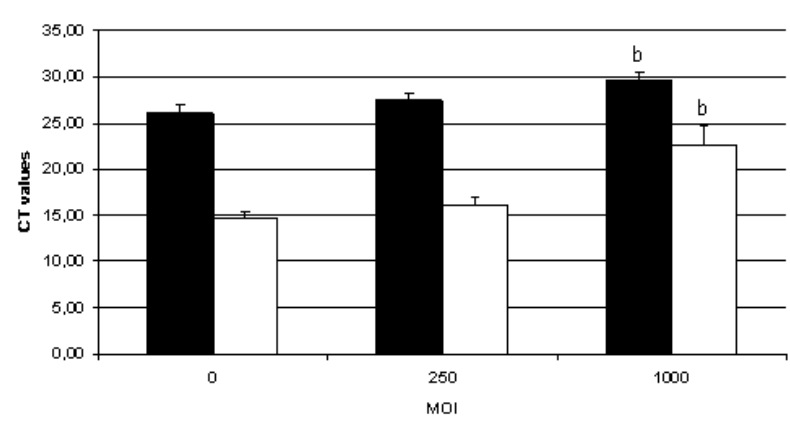

Figure 3 Cellular expression of TGF- $\beta 1$, type II collagen, aggrecan, and MMP-3 in osteoarthritic human chondrocytes and a normal human articular chondrocyte cell line following AAV-TGF- $\beta 1$ transduction. At day eight after transduction, total RNA was extracted and analysed by RT-PCR as described in the Material and Methods section (mean with SEM). AAV vector mediated TGF- $\beta 1$ gene delivery resulted in increased expressions of TGF$\beta 1$, type II collagen, and aggrecan, but decreased expression of MMP-3 $(\mathrm{p}<0.05)$.

$\square$ : values from a normal human articular chondrocyte cell line.

: values from human osteoarthritic chondrocytes.

a: Significantly different from control chondrocytes (not transduced and AAV-eGFP transduced) at MOI of 250 AAV-TGF- $\beta 1(p<0.05)$.

b: Significantly different from control chondrocytes (not transduced and AAV-eGFP transduced) at MOI of 1000 AAV-TGF- $\beta 1(\mathrm{p}<0.05)$.

increased TGF- $\beta 1$ mRNA expression levels matching the results of TGF- $\beta 1$ synthesis determined by ELISA. Hence, TGF- $\beta 1$ expression was increased by application of higher MOI of AAV-TGF- $\beta 1$. No difference was found in TGF$\beta 1$ expression between tsT/AC62 chondrocytes and osteoarthritic chondrocytes (Fig. 3,A).

In tsT/AC62 chondrocytes, treatment with AAV-TGF$\beta 1$ resulted in $26 \%(\mathrm{p}<0.022)$ higher expression level $(\mathrm{Ct})$ of type II collagen at a MOI of 1000 compared with uninfected chondrocytes. At a MOI of 250, only an insignificant $8 \%(\mathrm{p}=0.063)$ increase in expression level (Ct) of type II collagen could be observed. The relative gene expressions of type II collagen in tsT/AC62 chondrocytes were 9.3 at a MOI of 250 , and 113.6 at a MOI of 1000 (Table 2). Similarly, in osteoarthritic chondrocytes, AAV-TGF- $\beta 1$ transduction increased the expression level $(\mathrm{Ct})$ of type II collagen mRNA by $18 \%$ $(\mathrm{p}=0.012)$ at a MOI of 1000 (relative gene expression $=$ 52.5), but did not influence the type II collagen mRNA expression significantly at a MOI of 250 (5\% increase $(p=0.154)$. However, the relative gene expression was 8.3 (Table 2). Interestingly, the expression levels $(\mathrm{Ct})$ of type II collagen in the osteoarthritic chondrocytes were higher compared with the tsT/AC62 chondrocytes (MOI $=0 ; 43 \%$, $\mathrm{p}<0.01$. MOI $=250 ; 41 \%, \mathrm{p}<0.01$. MOI $=1000 ; 37 \%$, $\mathrm{p}<0.01)$. But the relative gene expressions of type II collagen at the corresponding MOI were lower in osteoarthritic chondrocytes compared with tsT/AC62 chondrocytes.

A $19 \%(p=0.019)$ increase in aggrecan mRNA expression $(\mathrm{Ct})$ and a relative gene expression of 199.9 at MOI of 1000 were detected in the AAV-TGF- $\beta 1$ treated tsT/AC62 chondrocytes. AAV-TGF- $\beta 1$ transduction of tsT/ AC62 chondrocytes at a MOI of 250 did not lead to a significant increase in mRNA expression $(6 \%$ increase $(p=0.197))$. The relative aggrecan gene expression was 8.7 in tsT/AC62 chondrocytes at a MOI of 250. The aggrecan mRNA expression $(\mathrm{Ct})$ in osteoarthritic chondrocytes was 
Table 2. Relative gene expressions of TGF- $\beta 1$, type II collagen, aggrecan, and MMP-3

\begin{tabular}{clcc} 
MOI of AAV-TGF-beta-1 & \multicolumn{1}{c}{ Gene } & T/AC62 & hOC \\
& TGF-beta1 & $13.5 \pm 2.5$ & $13.2 \pm 3.5$ \\
& Type II collagen & $9.3 \pm 2.2$ & $8.3 \pm 2.7$ \\
& Aggrecan & $8.7 \pm 3.1$ & $7.9 \pm 2.7$ \\
& MMP-3 & $0.8 \pm 0.4$ & $0.9 \pm 0.4$ \\
& TGF-beta1 & $321.6 \pm 42.0$ & $585.7 \pm 59.4$ \\
& Type II collagen & $113.6 \pm 18.6$ & $52.5 \pm 16.8$ \\
& Aggrecan & $199.9 \pm 19.4$ & $107.2 \pm 16.5$ \\
& MMP-3 & $0.11 \pm 0.03$ & $0.19 \pm 0.04$
\end{tabular}

T/AC62: normal adult human articular chondrocyte cell line, hOC: human osteoarthritic chondrocytes.

increased with $19 \%(\mathrm{p}<0.01)$, and the relative gene expression was 107.2 by AAV-TGF- $\beta 1$ transduction at MOI of 1000. At MOI of 250 no differences were found in $\mathrm{Ct}$ ( $5 \%$ increase $(\mathrm{p}=0.209)$. The corresponding relative gene expression was 7.9. Analogous to type II collagen expression, higher expression levels $(\mathrm{Ct})$ of aggrecan was found in osteoarthritic chondrocytes when compared with tsT/AC62 chondrocytes $(\mathrm{MOI}=0 ; 30 \%, \mathrm{p}<0.01$. $\mathrm{MOI}=250$; $29 \%, \mathrm{p}<0.01$. MOI $=1000 ; 30 \%, \mathrm{p}<0.01)$, but the equivalent relative gene expressions were lower.

Both expression $(\mathrm{Ct})$ and relative gene expression of MMP-3 were reduced in both tsT/AC62 chondrocytes and osteoarthritic chondrocytes when treated with AAV-TGF$\beta 1$ at MOI of $1000(\mathrm{Ct}=13 \%(\mathrm{p}=0.044)$; relative gene expression $=0.1$, and $\mathrm{Ct}=55 \%(\mathrm{p}<0.01)$; relative gene expression $=0.2$, respectively). When infecting with AAVTGF- $\beta 1$ at MOI of 250, no significant differences in $\mathrm{Ct}$ were found in tsT/AC62 chondrocytes or osteoarthritic chondrocytes when compared to uninfected chondrocytes. However, the relative MMP-3 gene expressions at the MOI of 250 were 0.8 in tsT/AC62 chondrocytes and 0.9 in osteoarthritic chondrocytes. In untransduced controls and at MOI of 250, higher expression levels $(\mathrm{Ct})$ of MMP-3 were observed in osteoarthritic chondrocytes compared with tsT/AC62 chondrocytes (MOI $=0 ; 44 \%, \mathrm{p}<0.01$. $\mathrm{MOI}=250 ; 42 \%, \mathrm{p}<0.01)$. But when treating with the AAVTGF- $\beta 1$ at a MOI of 1000 no significant difference in MMP-3 mRNA expression (Ct) was found between tsT/ AC62 chondrocytes and osteoarthritic chondrocytes $(\mathrm{p}=0.07)$.

\section{Discussion}

The present study shows that AAV-TGF- $\beta 1$ vector transduction of human articular chondrocytes increases cellular synthesis of TGF- $\beta 1$. In both primary osteoarthritic chondrocytes and a human normal articular chondrocyte cell line (tsT/AC62) this leads to increased expression of type II collagen and aggrecan, whereas the MMP-3 mRNA expression is decreased.

Traditional drug delivery methods cannot target specific joints or maintain effective concentrations of drugs for a long time. The challenge to gene-based treatment strategies is to devise methods that incorporate the correct gene or gene combination with the appropriate vector, delivered to specific target cells within the proper biological context to achieve a meaningful therapeutic response. In this perspective, the AAV vector might be an attractive tool toward the treatment and repair of damaged articular cartilage (Schwarz, 2000). AAV vectors have been demonstrated useful in transducing the three primary candidate cell types to target for genetic modification in order to treat joint diseases, which are synovial lining cells (Goater et al., 2000), normal chondrocytes (Arai et al., 2000; Madry et al., 2003; Ulrich-Vinther et al., 2002), and mesenchymal stem cells (MSCs) (Ito et al., 2004). In the present in vitro study, the chondro-metabolic consequences of AAV-TGF- $\beta 1$ gene delivery to both normal and osteoarthritic human chondrocytes were investigated. Our data demonstrates that the AAV-TGF- $\beta 1$ vector efficiently transduces both osteoarthritic human chondrocytes and a human normal articular chondrocyte cell line, and additionally indicates that normal articular chondrocytes and osteoarthritic chondrocytes are equally responsive to AAV vector mediated gene transduction. We found the transduction efficiencies are consistent with previous published data on normal primary human articular chondrocytes (Ulrich-Vinther et al., 2002). Madry et al have demonstrated that AAV-based vectors can efficiently transduce and stably express marker genes in articular chondrocytes of normal and osteoarthritic human articular cartilage (Madry et al., 2003). These experiments were based on repeated in vitro transductions of primary chondrocytes from one patient with osteoarthritis only. However, our results, based on separate paired studies of 
primary human osteoarthritic chondrocyte cultures derived from 8 patients, are backing-up the conclusion from Madry et al.

Furthermore, our study demonstrates the AAV-TGF$\beta 1$ transduction of normal and osteoarthitic human chondrocytes leads to elevated levels of endogenous bioactive TGF- $\beta 1$. Induction of increased TGF- $\beta 1$ synthesis in normal articular chondrocytes derived from various mammals have been demonstrated with other viral vector systems (Arai et al., 1997; Gelse et al., 2003; Shuler et al., 2000; Trippel et al., 2004). To our knowledge, TGF$\beta 1$ transduction of human articular chondrocytes has not yet been published.

Among the list of potentially useful cDNAs for cartilage repair are the anabolic growth factors of the TGFb superfamily (Izumi et al., 1992; Joyce et al., 1990; Moses et al., 1996), including TGF- $\beta 1-3$ (Worster et al., 2000), several of the bone morphogenetic proteins (BMPs) (Sato et al., 1984; Sellers et al., 1997; Wang et al., 1990), insulinlike growth factor (IGF)-1 (Fortier et al., 2002; Nixon et al., 2001; Trippel et al., 2004), fibroblast growth factors (FGFs) (Ellsworth et al., 2002; Hill et al, 1992), and epidermal growth factor (EGF) (Osborn et al., 1989). In particular, TGF- $\beta 1$ has been identified as a key factor as TGF- $\beta 1$ potentates expression of type II collagen and proteoglycans, enhances proliferation and differentiation, and appears to redifferentiate the phenotypically altered chondrocytes seen in osteoarthritic cartilage (Blumenfeld et al., 1997; Gouttenoire et al., 2004; Lafeber et al., 1997; Livne et al., 1994). Delivery by recombinant adenovirus of the cDNA for TGF- $\beta 1$, to monolayer cultures of chondrocytes isolated from experimental animals has been shown to stimulate expression of cartilage matrix genes, resulting in increased synthesis of proteoglycan and collagen type II (Shuler et al., 2000; Smith et al., 2000). TGF- $\beta 1$, IGF-1 and BMP-2 over-expression has also been found to rescue proteoglycan synthesis following pretreatment of the chondrocytes with IL-1, a potent inhibitor of matrix synthesis (Smith et al., 2000). In concordance with these studies, the present study shows that AAV vector mediated TGF- $\beta 1$ gene therapy upregulates the anabolic metabolism in both normal and osteoarthritic articular chondrocytes in vitro.

Osteoarthritis is characterized by high level of degradative enzymes such as MMPs that deteriorate normal articular cartilage. The present in vitro experiments demonstrate that AAV-TGF- $\beta 1$ transduced osteoarthritic human chondrocytes respond to the elevated endogenous production of TGF- $\beta 1$ by decreasing their synthesis of MMP-3. Down-regulation of MMP-3 expression by TGF$\beta 1$ has been demonstrated by other studies as well (Shlopov et al., 1999; Su et al., 1996). A indirect influencing of the TGF- $\beta 1$ signaling cascade via IL-1 signaling have been suggested (Kaiser et al., 2004; Moulharat et al., 2004). It is noteworthy that AAV vector mediated TGF- $\beta 1$ transfer to osteoarthritic chondrocytes and the normal articular chondrocyte cell line resulted in equal increases in TGF$\beta 1$ synthesis, but that the subsequent anabolic responses to this stimulus were more pronounced in the normal chondrocytes compared with the osteoarthritic chondrocytes. It might be that primary osteoarthritic chondrocytes, which are derived from deteriorated joints characterized by chronic inflammation, have become metabolically deranged, and, thus, unable to respond sufficiently to an anabolic stimulation. Comparisons of metabolic responses the immortalized articular chondrocyte cell line may also be a part of the explanation. The hypotheses must be investigated in advanced in vitro experiments and in vivo models of osteoarthritis.

It has been shown that frequent large doses, direct intraarticular injections of TGF- $\beta 1$ induce undesired effects such as synovium inflammation and osteophytes (van Beuningen et al., 1994). Concerning these problems, gene transduction has an advantage by changing the promoter area of the gene, specific therapeutic gene can be expressed in a target tissue. Hence, by using a tissue specific promoter for a certain collagen, e.g. type II collagen, it would be possible to limit TGF- $\beta 1$ expression on cartilage tissue and to reduce the severity of unwanted effects on other tissues. Furthermore, gene therapy approaches may be further improved by implementation of adjustable constructs such as RU486 (Hyder et al., 2000), TET (Lewandoski, 2001) sensitive promoter systems.

In conclusion, the present study demonstrates that both primary osteoarthritic human chondrocytes and a human normal articular chondrocyte cell line can be genetically manipulated by a recombinant AAV vector to produce and respond to the potentially therapeutic cytokine, TGF- $\beta 1$. This technology has a number of experimental and therapeutic applications, including those related to the study and treatment of arthritis and cartilage repair.

\section{Acknowledgements}

The project was supported by grants from the Danish Medical Research Council (22-02-0349CH/NP), the Beckett Foundation, and the Augustinus Foundation. Thanks to Anette Baatrup for her skillful technical assistance, and to Frank Madsen, Department of Orthopaedics, Aarhus University Hospital, Denmark, for providing access to the donor patients.

\section{References}

Alleyne KR, Galloway MT (2001) Management of osteochondral injuries of the knee. Clin Sports Med 20: 343-364.

Alsalameh S, Amin R, Gemba T, Lotz M (2004) Identification of mesenchymal progenitor cells in normal and osteoarthritic human articular cartilage. Arthritis Rheum 50: 1522-1532.

Andrews HJ, Edwards TA, Cawston TE, Hazleman BL (1989) Transforming growth factor- $\beta 1$ causes partial inhibition of interleukin 1-stimulated cartilage degradation in vitro. Biochem Biophys Res Commun 162: 144-150.

Arai Y, Kubo T, Fushiki S, Mazda O, Nakai H, Iwaki Y, Imanishi J, Hirasawa Y (2000) Gene delivery to human chondrocytes by an adeno associated virus vector. J Rheumatol 27: 979-982. 
Arai Y, Kubo T, Kobayashi K, Takeshita K, Takahashi K, Ikeda T, Imanishi J, Takigawa M, Hirasawa Y (1997) Adenovirus vector-mediated gene transduction to chondrocytes: in vitro evaluation of therapeutic efficacy of transforming growth factor- $\beta 1$ and heat shock protein 70 gene transduction. J Rheumatol 24:1787-1795.

Baragi VM, Renkiewicz RR, Qiu L, Brammer D, Riley JM, Sigler RE, Frenkel SR, Amin A, Abramson SB, Roessler BJ (1997) Transplantation of adenovirally transduced allogeneic chondrocytes into articular cartilage defects in vivo. Osteoarthritis Cartilage 5: 275-282.

Blumenfeld I, Laufer D, Livne E (1997) Effects of transforming growth factor- $\beta 1$ and interleukin- $1 \alpha$ on matrix synthesis in osteoarthritic cartilage of the temporomandibular joint in aged mice. Mech Ageing Dev 95: 101111.

Browne JE, Branch TP (2000) Surgical alternatives for treatment of articular cartilage lesions. J Am Acad Orthop Surg 8: 180-189.

Buckwalter JA, Mankin HJ (1998) Articular cartilage repair and transplantation. Arthritis Rheum 41: 1331-1342.

Bustin SA (2000) Absolute quantification of mRNA using real-time reverse transcription polymerase chain reaction assays. J Mol Endocrinol 25:169-193.

Doherty PJ, Zhang H, Tremblay L, Manolopoulos V, Marshall KW (1998) Resurfacing of articular cartilage explants with genetically-modified human chondrocytes in vitro. Osteoarthritis Cartilage 6:153-159.

Dowthwaite GP, Bishop JC, Redman SN, Khan IM, Rooney P, Evans DJ, Haughton L, Bayram Z, Boyer S, Thomson B, Wolfe MS, Archer CW (2004) The surface of articular cartilage contains a progenitor cell population. $\mathrm{J}$ Cell Sci 117: 889-897.

Ellsworth JL, Berry J, Bukowski T, Claus J, Feldhaus A, Holderman S, Holdren MS, Lum KD, Moore EE, Raymond F, Ren H, Shea P, Sprecher C, Storey H, Thompson DL, Waggie K, Yao L, Fernandes RJ, Eyre DR, Hughes SD (2002) Fibroblast growth factor-18 is a trophic factor for mature chondrocytes and their progenitors. Osteoarthritis Cartilage 10: 308-320.

Fortier LA, Mohammed HO, Lust G, Nixon AJ (2002) Insulin-like growth factor-I enhances cell-based repair of articular cartilage. J Bone Joint Surg Br 84: 276-288.

Frenkel SR, Di Cesare PE (1999) Degradation and repair of articular cartilage. Front Biosci 4: D671-D685.

Gelse K, von der MK, Schneider H (2003) Cartilage regeneration by gene therapy. Curr Gene Ther 3: 305-317.

Goater J, Muller R, Kollias G, Firestein GS, Sanz I,

O'Keefe RJ, Schwarz EM (2000) Empirical advantages of adeno associated viral vectors in vivo gene therapy for arthritis. J Rheumatol 27: 983-989.

Goater JJ, O'Keefe RJ, Rosier RN, Puzas JE, Schwarz EM (2002) Efficacy of ex vivo OPG gene therapy in preventing wear debris induced osteolysis. J Orthop Res 20:169-173.

Gouttenoire J, Valcourt U, Ronziere MC, AubertFoucher E, Mallein-Gerin F, Herbage D (2004) Modulation of collagen synthesis in normal and osteoarthritic cartilage. Biorheology 41: 535-542.

Grimaud E, Heymann D, Redini F (2002) Recent advances in TGF- $\beta 1$ effects on chondrocyte metabolism.
Potential therapeutic roles of TGF- $\beta 1$ in cartilage disorders. Cytokine Growth Factor Rev 13: 241-257.

Hill DJ, Logan A (1992) Peptide growth factors and their interactions during chondrogenesis. Prog Growth Factor Res 4: 45-68.

Hyder SM, Huang JC, Nawaz Z, Boettger-Tong H, Makela S, Chiappetta C, Stancel GM (2000) Regulation of vascular endothelial growth factor expression by estrogens and progestins. Environ Health Perspect 108 Suppl 5: 785-790.

Ito H, Goater JJ, Tiyapatanaputi P, Rubery PT, O’Keefe RJ, Schwarz EM (2004) Light-activated gene transduction of recombinant adeno-associated virus in human mesenchymal stem cells. Gene Ther 11: 34-41.

Izumi T, Scully SP, Heydemann A, Bolander ME (1992) Transforming growth factor- $\beta 1$ stimulates type II collagen expression in cultured periosteum-derived cells. J Bone Miner Res 7: 115-121.

Joyce ME, Roberts AB, Sporn MB, Bolander ME (1990) Transforming growth factor- $\beta 1$ and the initiation of chondrogenesis and osteogenesis in the rat femur. J Cell Biol 110: 2195-2207.

Kaiser M, Haag J, Soder S, Bau B, Aigner T (2004) Bone morphogenetic protein and transforming growth factor- $\beta 1$ inhibitory Smads 6 and 7 are expressed in human adult normal and osteoarthritic cartilage in vivo and are differentially regulated in vitro by interleukin-1. Arthritis Rheum 50: 3535-3540.

Kang R, Marui T, Ghivizzani SC, Nita IM, Georgescu HI, Suh JK, Robbins PD, Evans CH (1997) Ex vivo gene transfer to chondrocytes in full-thickness articular cartilage defects: a feasibility study. Osteoarthritis Cartilage 5: 139143.

Kish G, Modis L, Hangody L (1999) Osteochondral mosaicplasty for the treatment of focal chondral and osteochondral lesions of the knee and talus in the athlete. Rationale, indications, techniques, and results. Clin Sports Med 18: 45-66.

Lafeber FP, van Roy HL, van der Kraan PM, van den Berg WB, Bijlsma JW (1997) Transforming growth factor$\beta 1$ predominantly stimulates phenotypically changed chondrocytes in osteoarthritic human cartilage. J Rheumatol 24: 536-542.

Lewandoski M (2001) Conditional control of gene expression in the mouse. Nat Rev Genet 2:743-755.

Livne E (1994) In vitro response of articular cartilage from mature mice to human transforming growth factorß1. Acta Anat (Basel) 149: 185-194.

Lum ZP, Hakala BE, Mort JS, Recklies AD (1996) Modulation of the catabolic effects of interleukin-1 on human articular chondrocytes by transforming growth factor- $\beta 1$. J Cell Physiol 166: 351-359.

Madry H, Cucchiarini M, Terwilliger EF, Trippel SB (2003) Recombinant adeno-associated virus vectors efficiently and persistently transduce chondrocytes in normal and osteoarthritic human articular cartilage. Hum Gene Ther 14: 393-402.

Malemud CJ, Goldberg VM (1999) Future directions for research and treatment of osteoarthritis. Front Biosci 4: D762-D771. 
Martinek V, Fu FH, Lee CW, Huard J (2001) Treatment of osteochondral injuries. Genetic engineering. Clin Sports Med 20: 403-416.

Moses HL, Serra R (1996) Regulation of differentiation by TGF- $\beta 1$. Curr Opin Genet Dev 6: 581-586.

Moulharat N, Lesur C, Thomas M, Rolland-Valognes G, Pastoureau P, Anract P, De Ceuninck F, Sabatini M (2004) Effects of transforming growth factor- $\beta 1$ on aggrecanase production and proteoglycan degradation by human chondrocytes in vitro. Osteoarthritis Cartilage 12: 296-305.

Nixon AJ, Saxer RA, Brower-Toland BD (2001) Exogenous insulin-like growth factor-I stimulates an autoinductive IGF-I autocrine/paracrine response in chondrocytes. J Orthop Res 19: 26-32.

Osborn KD, Trippel SB, Mankin HJ (1989) Growth factor stimulation of adult articular cartilage. J Orthop Res 7: $35-42$.

Pfaffl MW (2001) A new mathematical model for relative quantification in real-time RT-PCR. Nucleic Acids Res 29: e45.

Redini F, Galera P, Mauviel A, Loyau G, Pujol JP (1988) Transforming growth factor- $\beta 1$ stimulates collagen and glycosaminoglycan biosynthesis in cultured rabbit articular chondrocytes. FEBS Lett 234: 172-176.

Robbins JR, Thomas B, Tan L, Choy B, Arbiser JL, Berenbaum F, Goldring MB (2000) Immortalized human adult articular chondrocytes maintain cartilage-specific phenotype and responses to interleukin-1. Arthritis Rheum 43: 2189-2201.

Sato K, Urist MR (1984) Bone morphogenetic proteininduced cartilage development in tissue culture. Clin Orthop Relat Res 183: 180-187.

Schwarz EM (2000) The adeno-associated virus vector for orthopaedic gene therapy. Clin Orthop Relat Res 379: S31-S39.

Sellers RS, Peluso D, Morris EA (1997) The effect of recombinant human bone morphogenetic protein-2 (rhBMP-2) on the healing of full-thickness defects of articular cartilage. J Bone Joint Surg Am 79: 1452-1463.

Shlopov BV, Smith GN, Jr., Cole AA, Hasty KA (1999) Differential patterns of response to doxycycline and transforming growth factor- $\beta 1$ in the down-regulation of collagenases in osteoarthritic and normal human chondrocytes. Arthritis Rheum 42: 719-727.

Shuler FD, Georgescu HI, Niyibizi C, Studer RK, Mi Z, Johnstone B, Robbins RD, Evans CH (2000) Increased matrix synthesis following adenoviral transfer of a transforming growth factor- $\beta 1$ gene into articular chondrocytes. J Orthop Res 18: 585-592.

Smith P, Shuler FD, Georgescu HI, Ghivizzani SC, Johnstone B, Niyibizi C, Robbins PD, Evans CH (2000) Genetic enhancement of matrix synthesis by articular chondrocytes: comparison of different growth factor genes in the presence and absence of interleukin-1. Arthritis Rheum 43: 1156-1164.

Su S, Dehnade F, Zafarullah M (1996) Regulation of tissue inhibitor of metalloproteinases-3 gene expression by transforming growth factor- $\beta 1$ and dexamethasone in bovine and human articular chondrocytes. DNA Cell Biol
15: 1039-1048.

Trippel SB, Ghivizzani SC, Nixon AJ (2004) Genebased approaches for the repair of articular cartilage. Gene Ther 11: 351-359.

Ulrich-Vinther M, Carmody EE, Goater JJ, balle S, O'Keefe RJ, Schwarz EM (2002) Recombinant adenoassociated virus-mediated osteoprotegerin gene therapy inhibits wear debris-induced osteolysis. J Bone Joint Surg Am 84: 1405-1412.

Ulrich-Vinther M, Duch MR, Soballe K, O'Keefe RJ, Schwarz EM, Pedersen FS (2004) In vivo gene delivery to articular chondrocytes mediated by an adeno-associated virus vector. J Orthop Res 22: 726-734.

Ulrich-Vinther M, Maloney MD, Goater JJ, Soballe K, Goldring MB, O’Keefe RJ, Schwarz EM (2002) Lightactivated gene transduction enhances adeno-associated virus vector-mediated gene expression in human articular chondrocytes. Arthritis Rheum 46: 2095-2104.

Ulrich-Vinther M, Maloney MD, Schwarz EM, Rosier R, O’Keefe RJ (2003) Articular cartilage biology. J Am Acad Orthop Surg 11: 421-430.

van Beuningen HM, Glansbeek HL, van der Kraan PM, van den Berg WB (2000) Osteoarthritis-like changes in the murine knee joint resulting from intra-articular transforming growth factor- $\beta 1$ injections. Osteoarthritis Cartilage 8: 25-33.

van Beuningen HM, van der Kraan PM, Arntz OJ, van den Berg WB (1994) Transforming growth factor- $\beta 1$ stimulates articular chondrocyte proteoglycan synthesis and induces osteophyte formation in the murine knee joint. Lab Invest 71: 279-290.

van der Kraan PM, van den Berg WB (2000) Anabolic and destructive mediators in osteoarthritis. Curr Opin Clin Nutr Metab Care 3: 205-211.

Vangsness CT, Jr. (1999) Overview of treatment options for arthritis in the active patient. Clin Sports Med 18:1-11.

Wang EA, Rosen V, D’Alessandro JS, Bauduy M, Cordes P, Harada T, Israel DI, Hewick RM, Kerns KM, LaPan P (1990) Recombinant human bone morphogenetic protein induces bone formation. Proc Natl Acad Sci U S A 87: 2220-2224.

Worster AA, Nixon AJ, Brower-Toland BD, Williams $J$ (2000) Effect of transforming growth factor- $\beta 1$ on chondrogenic differentiation of cultured equine mesenchymal stem cells. Am J Vet Res 61: 1003-1010.

Xiao X, Li J, Samulski RJ (1998) Production of hightiter recombinant adeno-associated virus vectors in the absence of helper adenovirus. J Virol 72: 2224-2232.

\section{Discussion with Reviewers}

Reviewer: The authors have shown that AAV mediated gene transfer of TGF- $\beta 1$ in both normal and osteoarthritic chondrocytes results in enhanced expression of TGF- $\beta 1$, Type-II collagen and Aggrecan, whilst reducing the expression of MMP-3. This was performed in 2dimensional culture plates where it is known that chondrocytes behave differently in $2 \mathrm{D}$ versus 3D environments; the former enhancing de-differentiation. 
Do the authors have experimental data or can they speculate on the possible effect of this gene transfer in both cell types when grown in 3D constructs?

Authors: This is an important issue raised by the reviewers. In vitro culturing of articular chondrocytes is a difficult task. It is evident that monolayer (2dimensional) culture conditions are not appropriate for long term studies of articular chondrocyte metabolism. In the present study, we have confirmed the metabolic maturity of the cultured chondrocytes by performing PCRanalyses on genes characterizing mature hyaline (articular) chondrocytes after eight days of culturing in monolayers (i.e. at the end of observation period). Hence, we demonstrated that de-differentiation of the articular chondrocytes did not occur with in the time span of the experiments. However, minor metabolic deterioration of the articular chondrocytes in the monolayer culture conditions metabolism can not be denied.

In previous studies (Ulrich-Vinther et al., 2002; Ulrich-Vinther et al., 2004), we have investigated the AAV vector transduction efficiencies in monolayer cultures of human articular chondrocyte, human articular cartilage explants, and in vivo models. In brief, the AAV vector mediated transduction efficiency of articular chondrocytes embedded in native 3-dimensional extra-cellular matrix decreases with the distance from cartilage surface. Thus, a decline in the number of chondrocytes, which are also expressing less trans-gene material, has been demonstrated in the remote parts of articular cartilage compared with chondrocytes located at the articular cartilage surface or at surfaces of cartilage injuries.

Novel studies investigating metabolism effects of bioactive proteins such as growth factors on articular chondrocytes cultured in three-dimensional scaffold have been initiated in our group. A synergistic effect of the three-dimensional environment and supplementation of appropriate signal proteins on hyaline cartilage genesis is hypothesized.

\section{Additional References}

Ulrich-Vinther M, Maloney MD, Goater JJ, Soballe K, Goldring MB, O'Keefe RJ, Schwarz EM (2002) Lightactivated gene transduction enhances adeno-associated virus vector-mediated gene expression in human articular chondrocytes. Arthritis Rheum 46: 2095-2104.

Ulrich-Vinther M, Duch MR, Soballe K, O'Keefe RJ, Schwarz EM, Pedersen FS (2004) In vivo gene delivery to articular chondrocytes mediated by an adeno-associated virus vector. J Orthop Res 22: 726-734. 